\title{
FSH1 regulates the phenotype and pathogenicity of the pathogenic dermatophyte Microsporum canis
}

\author{
FURONG ZHANG $^{1,2}$, CAN TAN $^{1}$, YU XU $^{3}$ and GUOLING YANG ${ }^{1}$ \\ ${ }^{1}$ Department of Dermatology, The First Affiliated Hospital of Dalian Medical University; \\ ${ }^{2}$ Department of Dermatology, Dalian Friendship Hospital, Dalian, Liaoning 116001; \\ ${ }^{3}$ Department of Dermatology, Hospital of Anjing Town, Chengdu, Sichuan 11736, P.R. China
}

Received May 31, 2019; Accepted September 3, 2019

DOI: $10.3892 /$ ijmm.2019.4355

\begin{abstract}
Microsporum canis (M. canis) is a common pathogen that causes tinea capitis and is present worldwide. The incidence of $M$. canis infection, particularly tinea capitis, has been increasing in China. In our previous studies, family of serine hydrolases 1 (FSH1) was identified as a potential virulence factor in tinea capitis infection caused by $M$. canis. To determine the function of this gene in M. canis, FSH1 was knocked down using double-stranded RNA interference mediated by Agrobacterium tumefaciens. Reverse transcription-quantitative PCR analysis was used to confirm gene knockdown. Loss of FSH1 expression by RNAi resulted in a minor phenotype alteration, but $M$. canis pathogenicity in guinea pig cutaneous infection was decreased compared with the wild-type strain. To the best of our knowledge, the present study is the first to demonstrate that FSH1 is associated with macroconidia septa formation and is an important contributor to $M$. canis virulence. These findings may advance the understanding of the function of the FSH1 gene and provide a foundation for future studies on macroconidia septa formation and pathogenicity of M. canis.
\end{abstract}

\section{Introduction}

Microsporum canis (M. canis) is a pathogenic fungus found in numerous regions of the world (1). $M$. canis primarily infects cats and dogs, but it is also contagious to other animals and humans through direct physical contact or indirect transmission through fungal-contaminated materials $(2,3)$. Furthermore, this fungus has the potential to cause outbreaks of dermatophytosis through stray cats and dogs $(4,5)$. Infections caused by $M$. canis are not well controlled. It has been reported that

Correspondence to: Professor Guoling Yang, Department of Dermatology, The First Affiliated Hospital of Dalian Medical University, 222 Zhongshan Road, Xigang, Dalian, Liaoning 116001, P.R. China

E-mail: yanggl@medmail.com.cn

Key words: Microsporum canis, family of serine hydrolases 1, phenotype, pathogenicity, RNA interference
M. canis is one of the most common dermatophytes to cause tinea capitis in humans in Europe, South America and Asia, particularly in India and China (6-11). As people in cities are likely to keep pets, the incidence of $M$. canis infections, and in particular tinea capitis, has increased in China during the last decade (12). In humans, this fungal disease is more common in prepubescent children (12), and immunocompromised individuals $(13,14)$. M. canis is a type of zoophilic fungi, and the clinical manifestations of tinea capitis infected by $M$. canis are intense inflammatory reactions, including severe itching of the scalp, red scaly papules around hair shafts and breaking-off of hairs $(15,16)$. In serious cases, the infection may cause permanent hair loss and leave cosmetic scars. As a result, M. canis infections affect patients physically and psychologically, and may be a significant burden for society $(17,18)$. However, the scientific literature regarding the virulence mechanisms of $M$. canis is limited. Therefore, there is an urgent need to understand the underlying mechanism of pathogenesis and thus, prevent it.

It has been reported that proteases secreted by M.canis and host immune reactions were associated with the pathogenic mechanisms of tinea capitis. The reported proteases, primarily keratinases, are represented by two families of subtilases and metalloproteases (19-22). Other proteases, such as cysteine dioxygenase, fungalysin and dipeptidyl peptidases have also been demonstrated to serve important roles in fungal infection (23-24). RNA interference technology has been shown to be an effective method for the investigation of the potential virulent genes of fungal species (25).

In a previous study, the family of serine hydrolases 1 (FSH1) gene was hypothesized to be a potential virulence gene of $M$. canis associated with tinea capitis (26). To verify this assumption, the gene function of FSH1 in the pathogenicity of M. canis was investigated in the present study. A FSH1 RNAi strain (FSH1-i mutant) was constructed and used for comparative studies with the wild-type strain to ascertain its virulence in vitro and in vivo.

\section{Materials and methods}

Fungal strains. A strain of $M$. canis was isolated from a recently-infected 5-year-old male patient with tinea capitis at The First Affiliated Hospital of Dalian Medical University 
(Dalian, China). M. canis was identified using standard phenotypic methods, including direct microscopic examination and fungal culture, and genotypic methods, including amplification of the internal transcribed spacer (ITS) region and sequence comparison with the NCBI GenBank database (http://www.ncbi.nlm.nih.gov/blast). Written informed consent from the patient's parents was obtained prior to isolation, and the protocols were approved by The First Affiliated Hospital of Dalian Medical University Ethics Board. The wild-type strain was used for the construction of FSH1 RNA interference.

Culturing conditions. The fungus was cultured on Sabouraud dextrose agar (SDA; glucose $40 \mathrm{~g} / 1$, peptone $10 \mathrm{~g} / 1$ and agar $15 \mathrm{~g} / \mathrm{l}$ ) at $27^{\circ} \mathrm{C}$ in a mold incubator with a humidity of $95 \%$ for 2 weeks. To extract DNA, the wild-type and the FSH1-i strains were cultured in Sabouraud dextrose broth (SDB; glucose $40 \mathrm{~g} / \mathrm{l}$ and peptone $10 \mathrm{~g} / \mathrm{l}$ ) at $27^{\circ} \mathrm{C}$ for 10 days with shaking at $100 \mathrm{rpm}$. To observe the macroconidia, the wild-type and the FSH1-i strains were maintained on rice medium (rice $300 \mathrm{~g} / \mathrm{l}$ ) at $27^{\circ} \mathrm{C}$.

For plasmid multiplication, the EHA105 strain of Agrobacterium tumefaciens (Dalian University of Technology) was grown in Luria-Bertani (LB; tryptone $10 \mathrm{~g} / \mathrm{l}$, yeast extract $5 \mathrm{~g} / \mathrm{l}$ and $\mathrm{NaCl} 10 \mathrm{~g} / \mathrm{l}$ ) medium with $50 \mu \mathrm{g} / \mathrm{ml}$ kanamycin and $20 \mu \mathrm{g} / \mathrm{ml}$ rifampicin at $28^{\circ} \mathrm{C}$ with shaking at $200 \mathrm{rpm}$. To create an inductive medium for RNA interference, acetosyringone $(200 \mu \mathrm{mol} / \mathrm{l})$ was added to the following medium as an inducer: Agar $15 \mathrm{~g} / \mathrm{l}, \mathrm{K}$-buffer $8 \mathrm{ml} / \mathrm{l}$, Mn-buffer $20 \mathrm{ml} / 1,1 \% \mathrm{CaCl}_{2} \cdot 2 \mathrm{H}_{2} \mathrm{O} 1 \mathrm{ml} / 1,0.01 \% \mathrm{FeSO}_{4}$ $10 \mathrm{ml} / 1,20 \% \mathrm{NH}_{4} \mathrm{NO}_{3} 2.5 \mathrm{ml} / \mathrm{l}, 50 \%$ glycerine $10 \mathrm{ml} / 1,1 \mathrm{M}$ 2-(N-orpholino) ethanesulfonic acid $40 \mathrm{ml} / \mathrm{l}, 20 \%$ glucose $10 \mathrm{ml} / \mathrm{l}$. For screening for FSH1 interference isolates, hygromycin $(100 \mathrm{mg} / \mathrm{l})$ and cefotaxime $(200 \mu \mathrm{M})$ were also added to the inductive medium.

Molecular identification of the wild-type strain through amplification of the ITS region. Fungal genomic DNA was extracted using the benzyl chloride extraction method and purified with phenol-chloroform as previously described (27). The ITS region was amplified by PCR. The PCR mixture contained $50 \mathrm{ng}$ of template DNA, $1 \mu 1$ each primer, $12.5 \mu \mathrm{M}$ 2x PCR Master-mix (BioTeke Corporation), and was made to a final volume of $20 \mu \mathrm{l}$ using purified water. The contiguous ITS1, 5.8S and ITS2 regions of the ribosomal DNA complex were amplified using the pair of conserved primers: ITS1 (forward, 5'-TCCGTAGGTGAACCTGCGG-3') and ITS4 (reverse, 5'-TCCTCCGCTTATTGATATGC-3') (28). The thermocycling conditions for PCR were as follows: Initial denaturation at $95^{\circ} \mathrm{C}$ for $5 \mathrm{~min}$, followed by 35 cycles of $95^{\circ} \mathrm{C}$ for $30 \mathrm{sec}, 55^{\circ} \mathrm{C}$ for $30 \mathrm{sec}$ and $72^{\circ} \mathrm{C}$ for $30 \mathrm{sec}$; with a final extension at $72^{\circ} \mathrm{C}$ for $5 \mathrm{~min}$. PCR products were isolated by electrophoresis using a $2 \%$ agarose gel, and sequenced by Sanger method. The resulting sequences were compared with the NCBI GenBank database.

Total RNA isolation and gene cloning. The wild-type M. canis strain was cultured in SDB at $27^{\circ} \mathrm{C}$ for 10 days with shaking at $100 \mathrm{rpm}$. The cultures were harvested and ground in liquid nitrogen. Total RNA was extracted with TRIzol ${ }^{\circledR}$ reagent
(Invitrogen; Thermo Fisher Scientific, Inc.) according to the manufacturer's protocol. cDNA was synthesized from $500 \mu \mathrm{g}$ of total RNA using PrimeScript ${ }^{\mathrm{TM}}$ II High Fidelity RT-PCR kit (Takara Bio, Inc.) according to the manufacturer's protocol. The temperature conditions were $30^{\circ} \mathrm{C}$ for $10 \mathrm{~min}, 42^{\circ} \mathrm{C}$ for $60 \mathrm{~min}$ and $70^{\circ} \mathrm{C}$ for $15 \mathrm{~min}$. The sequences of the primers used are listed in Table I. The primer sequences were designed based on the FSH1 gene which was screened from a differential gene expression cDNA library from our previous study (26). The PCR product was sequenced, and the sequence was the same as the known FSH1 gene. To obtain the full-length cDNA sequence of the FSH1 gene, 3'-rapid amplification of cDNA ends (RACE) and 5'-RACE amplification were performed using 3'-Full RACE Core Set with PrimeScript ${ }^{\mathrm{TM}}$ RTase kit (Takara Bio, Inc.) and the 5'-Full RACE with TAP kit (Takara Bio, Inc.) according to the manufacturer's protocols. The temperature conditions for $3^{\prime}-\mathrm{RACE}$ amplification were $42^{\circ} \mathrm{C}$ for $60 \mathrm{~min}$ followed by $70^{\circ} \mathrm{C}$ for $15 \mathrm{~min}$. The temperature conditions for $5^{\prime}-\mathrm{RACE}$ amplification were $30^{\circ} \mathrm{C}$ for $10 \mathrm{~min}$, $42^{\circ} \mathrm{C}$ for $60 \mathrm{~min}$ and $70^{\circ} \mathrm{C}$ for $15 \mathrm{~min}$. Outer and inner reactions were subsequently performed for nested PCR. The outer PCR mixture for 5'-RACE was as follows: $1 \mu 1 \mathrm{cDNA}$; $25 \mu 1$ 2X Gflex Buffer (Takara Bio, Inc.); $1 \mu 1$ Tks Gflex DNA Polymerase (1.25 U/ $\mu \mathrm{l})$ (Takara Bio, Inc.); $2 \mu 1$ 5'-RACE outer primer $(10 \mu \mathrm{M}) ; 1 \mu \mathrm{l} \mathrm{FSH1-reversel-YZ} \mathrm{primer}(20 \mu \mathrm{M})$; and

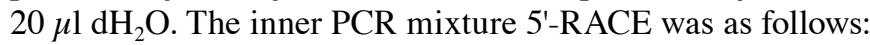
$1 \mu \mathrm{l}$ outer PCR product; $25 \mu \mathrm{l} 2 \mathrm{X}$ Gflex Buffer Pus); $1 \mu \mathrm{l}$ Tks Gflex DNA Polymerase; $2 \mu 1$ 5'-RACE inner primer (forward,

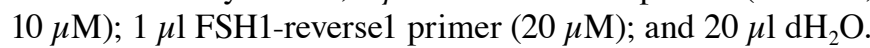
The thermocycling conditions for the outer and inner reactions were as follows: Initial denaturation at $94^{\circ} \mathrm{C}$ for $1 \mathrm{~min}$; followed by 30 cycles of $98^{\circ} \mathrm{C}$ for $10 \mathrm{sec}, 55^{\circ} \mathrm{C}$ for $15 \mathrm{sec}$ and $68^{\circ} \mathrm{C}$ for $1 \mathrm{~min}$. The nested PCR for $3^{\prime}-\mathrm{RACE}$ was the same as 5'-RACE, other than the primers. The primers for outer PCR were 3'-RACE outer primer and FSH1-forward1-YZ primer, and the primers for inner PCR were 3 '-RACE inner primer and FSH1-forward1 primer. The PCR products of 3'-RACE were sequenced. The PCR products of 5'-RACE were cloned into the T-Vector $\mathrm{pMD}^{\mathrm{TM}} 20$ vector (Takara Bio, Inc.) and sequenced.

Construction of pCB309-PFUFT-FSH1 knockdown vector. The pCB309 plasmid synthesized from pSilent-1 (Fungal Genetics Stock Center) was kindly provided by Zhang et al (29), and contained the Escherichia coli (E. coli) hygromycin B phosphotransferase gene to select successfully-transformed fungi, a transcription promoter driven by the Aspergillus nidulans constitutive trpC promoter and two multiple cloning sites separated by an intron-containing spacer. The pUC-PUT plasmid was synthesized by Wuhan GeneCreate Biological Engineering Co., Ltd. A map of each construct is presented in Fig. 1. The FSH1 forward inference sequence was amplified from the plasmid containing the full-length cDNA sequence of the FSH1 gene with the FSH1 primers presented in Table I. The PCR mixture was as follows: $1.25 \mathrm{U}$ LA Taq (Takara Bio, Inc.), $1 \mu \mathrm{l} \mathrm{FSH1} \mathrm{plasmid} \mathrm{(20} \mathrm{ng/} \mu \mathrm{l}), 1 \mu \mathrm{l} \mathrm{FSH1-F}$ primer, $1 \mu \mathrm{l}$ FSH1-R primer, $5 \mu 1$ 10X LA Taq Buffer, $4 \mu \mathrm{l}$ dNTP $(2.5 \mathrm{mM})$, and $\mathrm{ddH}_{2} \mathrm{O}$ up to a total volume of $50 \mu \mathrm{l}$. The thermocycling conditions were as follows: Initial denaturation at $94^{\circ} \mathrm{C}$ for $1 \mathrm{~min}$; followed by 30 cycles of $94^{\circ} \mathrm{C}$ 
Table I. Sequences of primers used in the present study.

Primer name

Sequence (5'-3')

3'RACE outer primer

3'RACE inner primer

5'RACE outer primer

5'RACE inner primer

FSH1-F1

FSH1-R1

FSH1-F1-YZ

FSH1-R1-YZ

3'RACE YZF1

3'RACE YZF2

3'RACE YZR1

FSH1-F

FSH1-R

CCGTCGTTCCACTAGTGATTT
CGCGGATCCTCCACTAGTGATTTCACTATAGG
CTAGGCTACATGCTGACAGCCTA
CGCGGATCCACAGCCTACTGATGATCAGTCGAT
CGCTGACGCTGTCATATTTC
CTGGCTGAACCCGAAGATGC
CCCCTTTTACTCCCATACGC
TCGCAGCCTTGATATTATTG
GATTCAGATCCCAACCGTCC
CTGTGTCTTCATGGCGTTGG
CTATAACTGAGCCAGGAG
CGGGGTACCCTCGAGTCCACGATCCTCTCTTCCCT
GAAGATCTAAGCTTATAACTGAGCCAGGAGCCAA-

CCGTCGTTCCACTAGTGATTT

CGCGGATCCTCCACTAGTGATTTCACTATAGG

CTAGGCTACATGCTGACAGCCTA

CGCTGACGCTGTCATATTTC

CTGGCTGAACCCGAAGATGC

CCCCTTTTACTCCCATACGC

TCGCAGCCTTGATATTATTG

GATTCAGATCCCAACCGTCC

CTGTGTCTTCATGGCGTTGG

CGGGGTACCCTCGAGTCCACGATCCTCTCTTCCCT

GAAGATCTAAGCTTATAACTGAGCCAGGAGCCAA-

RACE, rapid amplification of cDNA ends; FSH1, family of serine hydrolases 1; F, forward; R, reverse; YZ, verified.

for $30 \mathrm{sec}, 55^{\circ} \mathrm{C}$ for $45 \mathrm{sec}$ and $72^{\circ} \mathrm{C}$ for $30 \mathrm{sec}$, and a final extension $72^{\circ} \mathrm{C}$ for $10 \mathrm{~min}$. PCR products were gel purified using a Universal DNA Purification kit (Tiangen Biotech Co., Ltd.). To construct the final FSH1 double-stranded RNA interference (dsRNAi) plasmid pCB309-PFUFT, three steps of ligation were performed as follows. First, the purified product of PCR for the FSH1 gene was ligated into pUC-PUT following DNA digestion with XhoI and HindIII, and ligated by T4 DNA ligase (Invitrogen; Thermo Fisher Scientific, Inc.). The product was termed pUC-PFUT. The FSH1 gene was then ligated into pUC-PFUT following digestion with $B g l \mathrm{II}$ and $K p n I$ and ligated by T4 DNA ligase (Invitrogen; Thermo Fisher Scientific, Inc.) and this was called pUC-PFUFT. Finally, the two plasmids, pUC-PFUFT and pCB309 were digested using SpeI and SacI, purified using a Universal DNA Purification kit (Tiangen Biotech Co., Ltd.) and ligated using T4 DNA ligase (Invitrogen; Thermo Fisher Scientific, Inc.) to construct the final FSH1 dsRNAi plasmid, pCB309-PFUFT. Intermediate and final vectors were propagated in $E$. coli DH5 $\alpha$ cells (Beijing Huayueyang Biotechnology Co., Ltd.), purified by plasmid mini-preparations (Nucleospin Plasmid kit; Macherey-Nagel GmbH and Co. KG) and confirmed by a series of restriction enzyme digestions, followed by $1 \%$ agarose gel electrophoresis.

Construction of FSH1 interference mutants. The transformation procedure was performed as previously described by Zhang et al (30). Control strains were transformed with pCB309. Transformed A. tumefaciens strains containing the appropriate binary vector were grown on LB medium with antibiotics $(50 \mu \mathrm{g} / \mathrm{ml}$ kanamycin and $50 \mu \mathrm{g} / \mathrm{ml}$ rifamycin) for $48 \mathrm{~h}$ at $28^{\circ} \mathrm{C}$. M. canis conidia were grown on rice medium. The conidia were washed with sterile water. The same volume of conidia of $M$. canis $\left(5 \times 10^{6} / \mathrm{ml}\right)$ and transformed A.tumefaciens were mixed and co-cultured in the inductive medium on a shaker at $130 \mathrm{rpm}$ at $28^{\circ} \mathrm{C}$ for $6-8 \mathrm{~h}$ until the absorbance of the mixed cultured medium was adjusted to 0.7 at a wavelength of $660 \mathrm{~nm}$. The transformants were selected for using medium containing hygromycin $(100 \mathrm{mg} / \mathrm{l})$ and cefotaxime $(200 \mu \mathrm{M})$.

Reverse transcription-quantitative (RT-q)PCR. To measure the changes in the expression levels of FSH1 mRNA, RT-qPCR was performed. Fungal RNA was extracted using TriPure reagent (Roche Diagnostics) according to the manufacturer's protocols. RT was performed with PrimeScript ${ }^{\mathrm{TM}}$ II High Fidelity RT-PCR kit as aforementioned. qPCR reactions were performed using $10 \mu \mathrm{l}$ SYBR Green master mix, $1 \mu \mathrm{l}$ first strand cDNA, $0.4 \mu \mathrm{M}$ of each primer and $\mathrm{dH}_{2} \mathrm{O}$ to a final volume of $20 \mu \mathrm{l}$. The $18 \mathrm{~S}$ ribosomal gene was used as an endogenous control (26). The sequences of the primers used were as follows: FSH1 forward, 5'-CAGATAGCACAGGCG GTTGA-3' and reverse, 5'-GGCGGATGCTTGTTGTCG-3'; and $18 \mathrm{~S}$ forward, 5'-AACTTAAAGGAATTGACGGAA-3' and reverse, 5'-CATCACAGACCTGTTATTGC-3'. The thermocycling conditions were as follows: Initial denaturation at $94^{\circ} \mathrm{C}$ for $5 \mathrm{~min}$; followed by 40 cycles of $94^{\circ} \mathrm{C}$ for $10 \mathrm{sec}, 60^{\circ} \mathrm{C}$ for $20 \mathrm{sec}$ and $72^{\circ} \mathrm{C}$ for $30 \mathrm{sec}$; and a final extension at $68^{\circ} \mathrm{C}$ for $5 \mathrm{~min}$. The $2^{-\Delta \Delta \mathrm{Cq}}$ method was used to calculate relative expression (31), which was subsequently expressed as a percentage of the mean value obtained for at least two pCB309-transformed control samples per run. Negative control (water as template) was included in each run.

Growth properties assay and microscopic analysis. The M. canis wild-type strain and the FSH1-i mutant were cultured on SDA-containing plates and rice medium at $27^{\circ} \mathrm{C}$ in a mold incubator with humidity of $95 \%$ for 2 weeks. The diameter of the fungal colonies on SDA-containing plates was measured and the morphologic features of the colonies in the two media were observed and recorded every two days. To characterize the mutant phenotype more precisely, the mycelium and macroconidia grown on rice medium were stained with lactophenol cotton blue at room temperature for $2 \mathrm{~min}$ and observed 
under a light microscope with magnification $\mathrm{x} 100$. The experiments were performed in duplicate, and each experiment was repeated twice at different times.

Scanning and transmission electron microscopy (SEM and $T E M$ ). To determine ultrastructural alterations of $M$. canis prior to and following FSH1 gene- knockdown, SEM and TEM were used to observe the cultured fungal colonies. Samples were prepared for transmission electron microscopy as described by Basma et al (32). Electron micrographs were generated using a Hitachi HT7700 electron microscope (Hitachi, Ltd.) at $100 \mathrm{kV}$. Samples were prepared for scanning electron microscopy as described by Wang et al (33). Dried colonies were coated with platinum-vanadium and observed under a Supra55 scanning electron microscope (Carl Zeiss AG) at $15 \mathrm{kV}$. All assays were performed in triplicate.

Infection of guinea pigs. A total of 10 female guinea pigs aged 7-10 weeks (weight, 200-300 g) were obtained from the Laboratory Animal Center of Dalian Medical University (Dalian, China). The guinea pigs were maintained under standard conditions at a temperature of $20^{\circ} \mathrm{C}$ at $5 \%$ humidity in a 12-h light/dark cycle with free access to food and water for 7 days prior to performing the experiment. All the animal experimental methods and operations were approved by The Dalian Medical University Animal Ethics Committee. The guinea pigs were randomly divided into two groups; the test group contained 8 guinea pigs and the control group contained 2 guinea pigs. Each animal was caged separately. Cutaneous fungal infection in the animals were developed as described previously with slight modifications (34). Briefly, all the guinea pigs were subjected to intraperitoneal injection of hydrocortisone $(10 \mathrm{mg} / \mathrm{kg})$ every day for 5 days prior to inoculation, and then once every other day until the end of the study. The animals were anesthetized by intraperitoneal injection of $10 \%$ chloral hydrate $(300 \mathrm{mg} / \mathrm{kg})$; the dose of the chloral hydrate was adapted from published studies (35-38). The parameters that were used to monitor the depth of analgesia were as follows: i) Respiratory amplitude and rhythm; ii) eye movement, tearing and pupillary light reflex; iii) skeletal muscle reaction (e.g., body movement and struggle); and iv) hind limb reflex to pinch with hemostatic forceps (38). When the animals were fully anesthetized, an area of $2.5 \times 2.5 \mathrm{~cm}^{2}$ on the abdomen of each animal was shaved and superficially injured using a sterile scalpel blade. One side of the flank was infected with the FSH1-i strain in $200 \mu \mathrm{l}$ aliquots $\left(1 \times 10^{7}\right.$ colony-forming units in $0.9 \%$ sterile sodium chloride), while the opposite flank was infected with an equal number of colony-forming units of the wild-type strain. Equal volumes of $0.9 \%$ sterile sodium chloride solution was applied to two guinea pigs as a control. Guinea pigs were observed daily after inoculation. Changes to the infected skin, such as signs of inflammation, degree of scurf and hair growth were recorded (34). At day 14 following inoculation, skin biopsies were taken from 3 guinea pigs randomly selected from the test group and 1 guinea pig from the control group after being anesthetized, as aforementioned. The condition of infected hairs was examined following treatment with $10 \%$ potassium hydroxide solution at room temperature for $5 \mathrm{~min}$, followed by gentle heating with an alcohol lamp for 3-4 sec. After

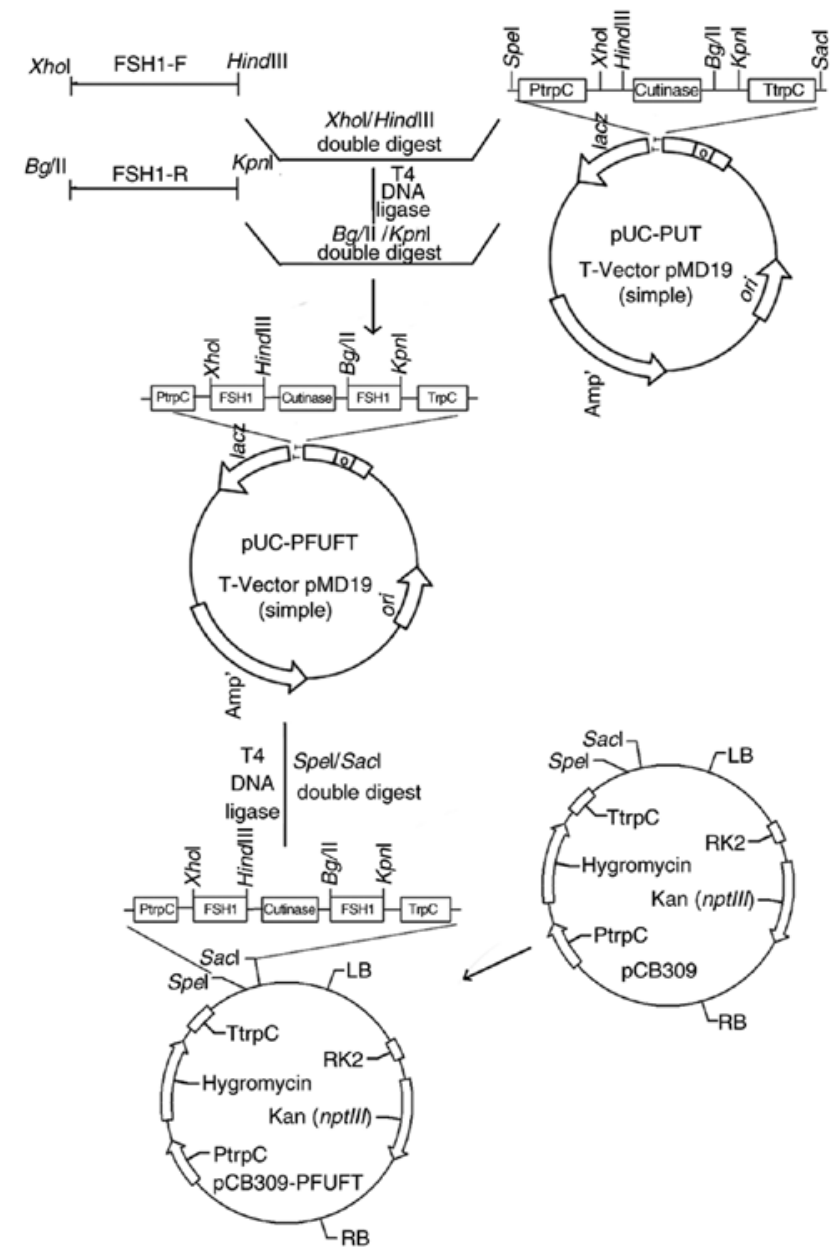

Figure 1. Construction of the knockdown vector pCB309-PFUFT. The FSH1 cDNA was ligated into pUC-PUT after DNA digestion by XhoI and HindIII to construct plasmid pUC-PFUFT. The two plasmids, pUC-PFUFT and pCB309 were digested by SpeI and SacI and ligated with T4 DNA ligase to construct the final FSH1 double stranded RNA interference plasmid pCB309-PFUFT. FSH1, family of serine hydrolases 1.

skin biopsies, the anesthetized animals were immediately transferred to a carbon dioxide chamber with a flow rate of $20 \%$ of the chamber volume/minute for euthanasia according to the guidelines of the Animal Ethics Committee of Dalian Medical University. The other remaining guinea pigs were euthanized on 30 days after inoculation. Tissues from the biopsies were fixed in $10 \%$ buffered formalin at room temperature overnight and embedded in paraffin for tissue sectioning. The tissue sections were stained with hematoxylin and eosin solution and Alcian blue periodic acid-Schiff (AB-PAS) at room temperature for $50 \mathrm{~min}$ for each stain. The degree of inflammation of the epidermal layers (including the stratum corneum, stratum spinosum and stratum granulosum), as well as the dermis was evaluated according to the degree of thickening and inflammation as follows: 0 , absent; 1 , mild; 2 , moderate; 3 , significant; and 4 , severe.

Statistical analysis. Data are presented as the mean \pm standard deviation, and a one-way ANOVA was used for statistical comparisons between different groups. The tests were performed using SPSS version 18.0 (SPSS, Inc.). P $<0.05$ was considered to indicate a statistically significant difference. 


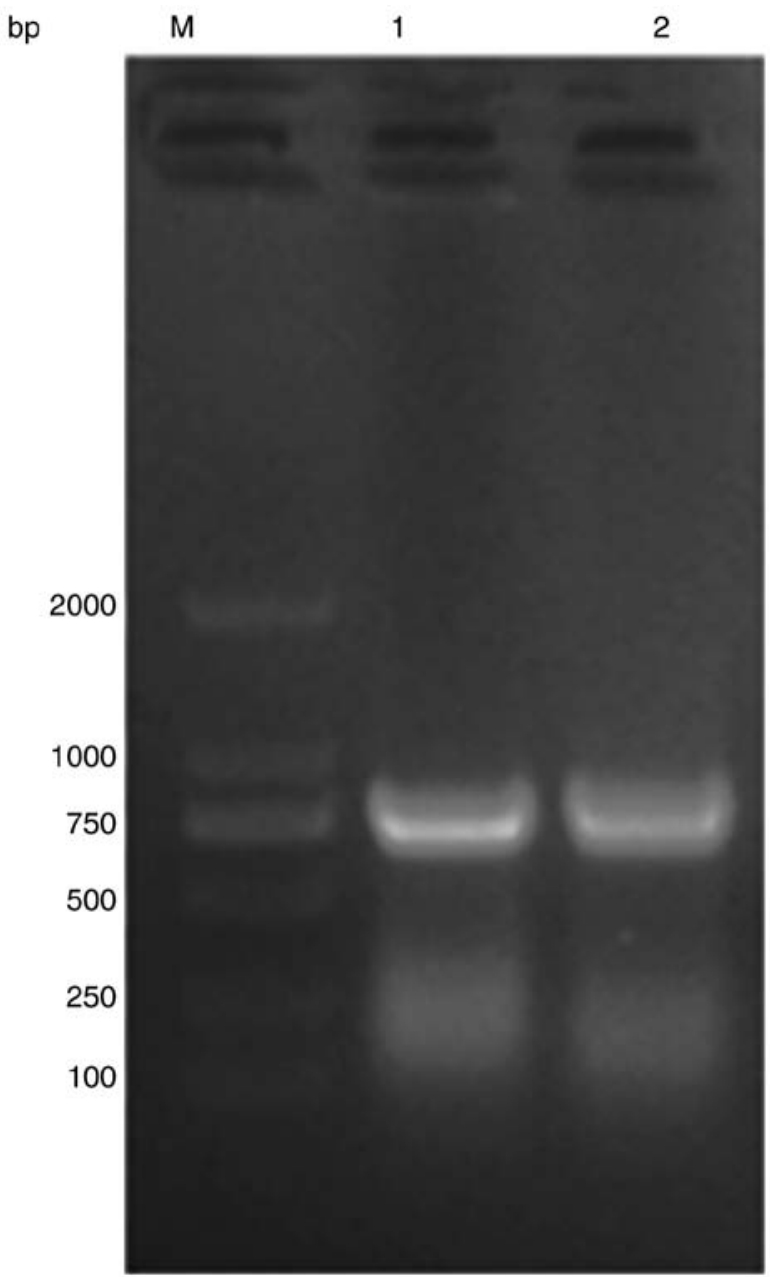

Figure 2. PCR amplification of the internal transcribed spacer region of the M. canis wild-type strain. The band was $\sim 760$ bp in length. Lanes: M, Marker DL2000; Lanes 1 and 2, M.canis wild-type strain. M.canis, Microsporum canis.

\section{Results}

Molecular characterization and genotyping of the M. canis wild-type strain. The ITS region of the M. canis wild-type strain was $\sim 760$ bp in length (Fig. 2; lane 1 and 2). The ITS sequence of the wild-type strain analyzed by BLAST in GenBank was $99 \%$ identical to the ITS sequence of $M$. canis in the databank (data not shown).

FSH1 expression is downregulated in the FSH1-i mutant. The transformants exhibited steady growth with a normal growth rate and phenotype after five passages. To assay FSH1 gene knockdown, RT-qPCR was used to evaluate target mRNA expression. RT-qPCR analysis demonstrated that the degree of knockdown was stable and efficient, and the expression of the FSH1 gene in FSH1-i mutant was $~ 70 \%$ lower compared with the wild-type strain (Fig. 3).

Phenotypic characterization of FSH1-i mutants. The morphology of the colonies produced by the wild-type and FSH1-i strains are presented in Fig. 4A and B. The diameter of the colonies of the wild-type strain and FSH1-i mutants did not display any notable morphological differences when cultured on both the SDA solid medium and rice medium at $25^{\circ} \mathrm{C}$ at any

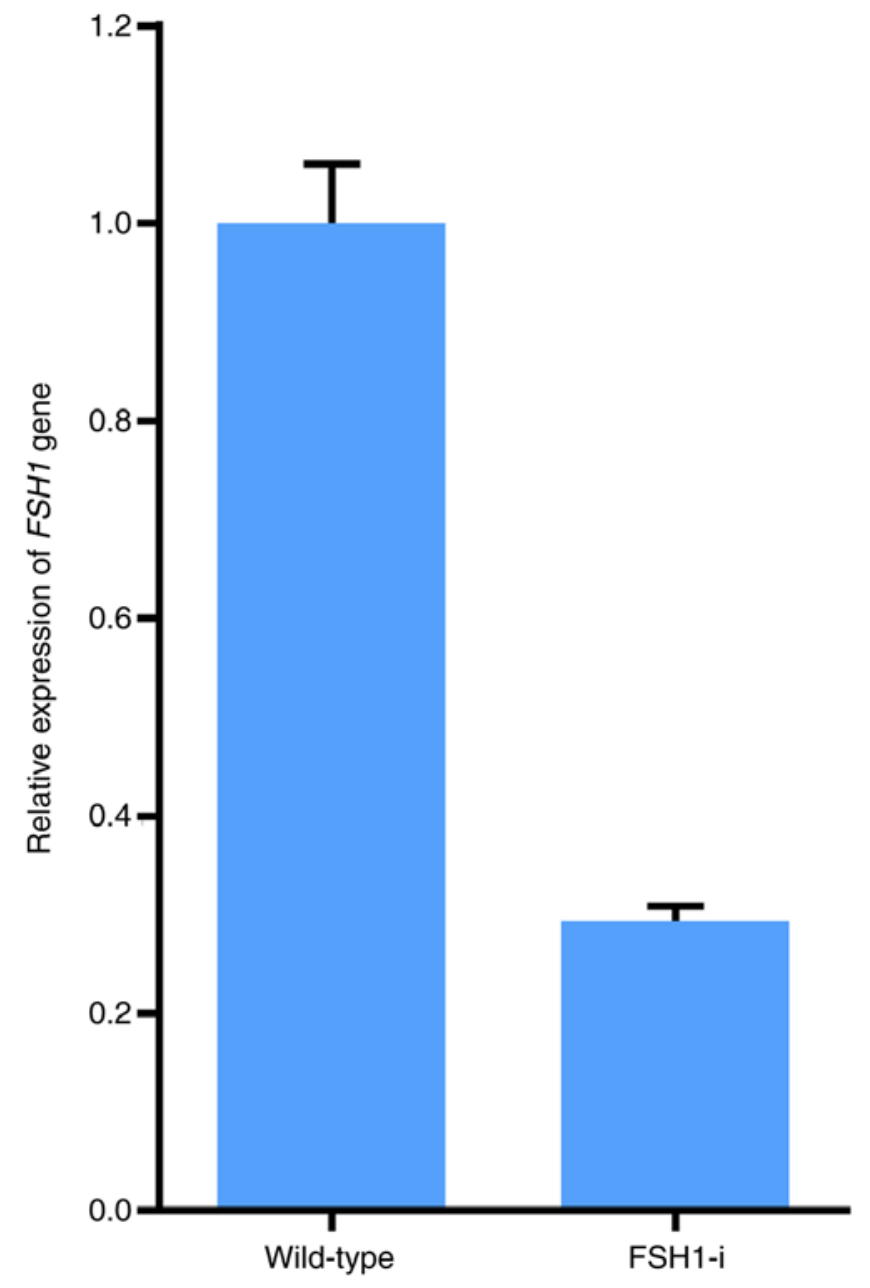

Figure 3. mRNA expression levels of FSH1 in wild-type and FSH1-i mutant Microsporum canis. Expression in the FSH1-i mutant was $70 \%$ lower compared with expression in the wild-type strain. FSH1, family of serine hydrolases 1; FSH1-i, FSH1 RNAi.

time point during the 14 days of observation. On the 7 th day, the color of the wild-type strain colonies did not notably differ from the FSH1-i mutant. However, on the 14th day, the color of the colonies of the wild-type strain appeared more orange compared with the FSH1-i mutant when cultured on both the SDA solid medium and rice medium, and the colonies were thinner in the wild-type compared with the FSH1-i mutant when cultured on rice medium (Fig. 4B). The shape of the wild-type strain and FSH1-i mutants were spindle-like, but the macroconidia septa of the FSH1-i mutant exhibited a reduced number or complete loss, as observed under a microscope following cotton blue staining (Fig. 4C). The size and shape of the growing hyphae did not appear different between the wild-type strain and the FSH1-i mutant.

Ultrastructural analysis by SEM. SEM micrographs revealed that the hyphae of the FSH1-i strain did not exhibit any visible changes when compared with the wild-type strain. Both strains exhibited hyphae with normal and continuous growth patterns. The macroconidia of the FSH1-i strain were typical, with a warty and spindle appearance. The macroconidia of the wild-type strain had a reproductive organelle with a well-defined surface (Fig. 5A). In the FSH1-i strain, there were 
A Day 7

Day 14
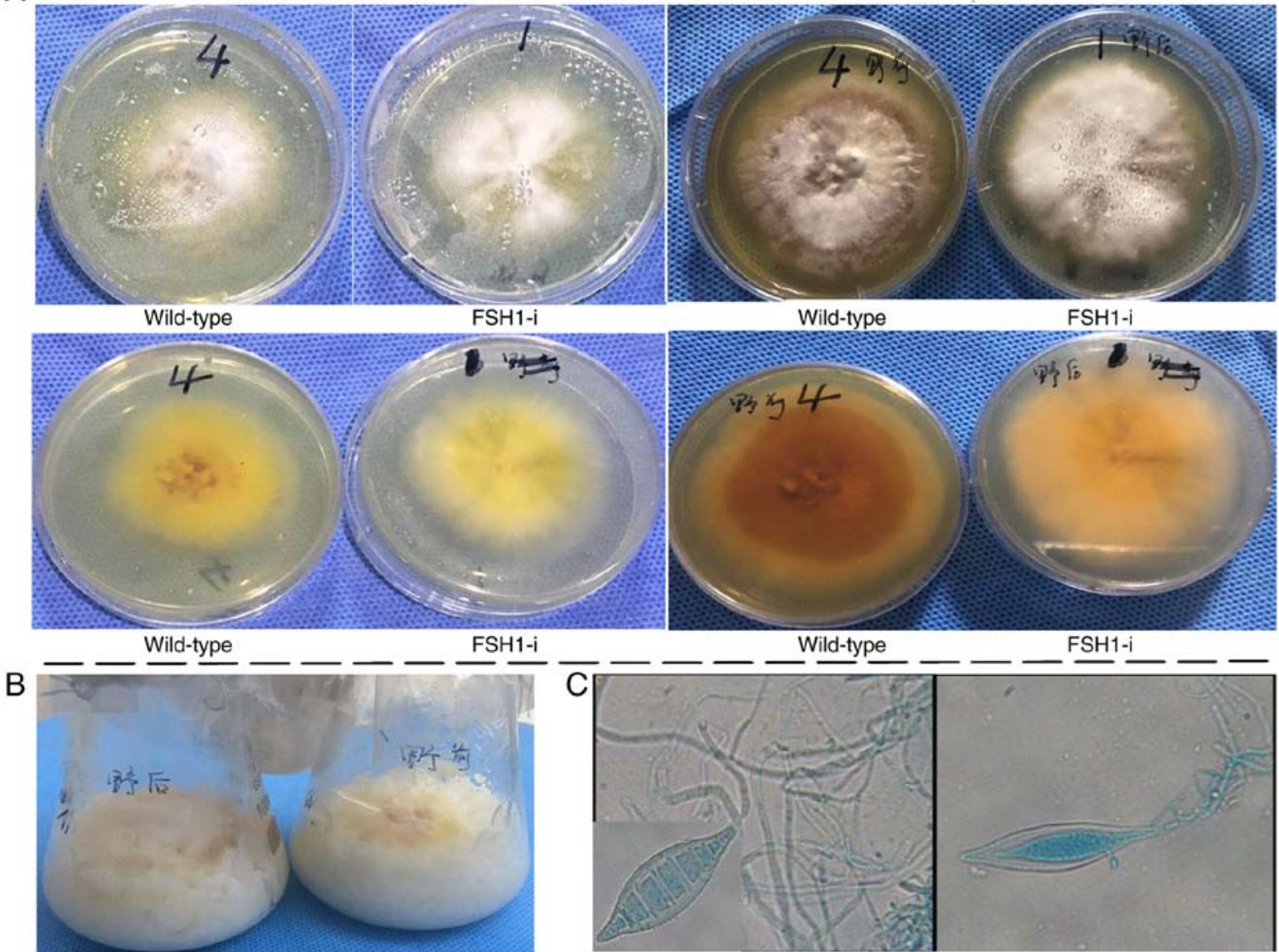

FSH1-i

Wild-type

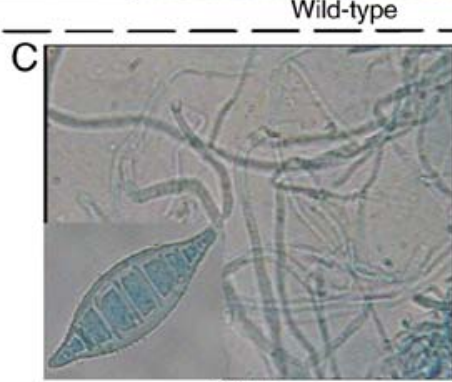

Wild-type

FSH1-i

Figure 4. Growth of wild-type and FSH1-i mutant strains of Microsporum canis. (A) Colonies grown on Sabouraud dextrose agar at day 7 and day 14 (B) Colonies grown on rice medium at day 7. (C) Colonies grown on rice medium for 7 days observed by light microscopy (magnification x100). The assays were repeated three times. FSH1, family of serine hydrolases 1; FSH1-i, FSH1 RNAi.
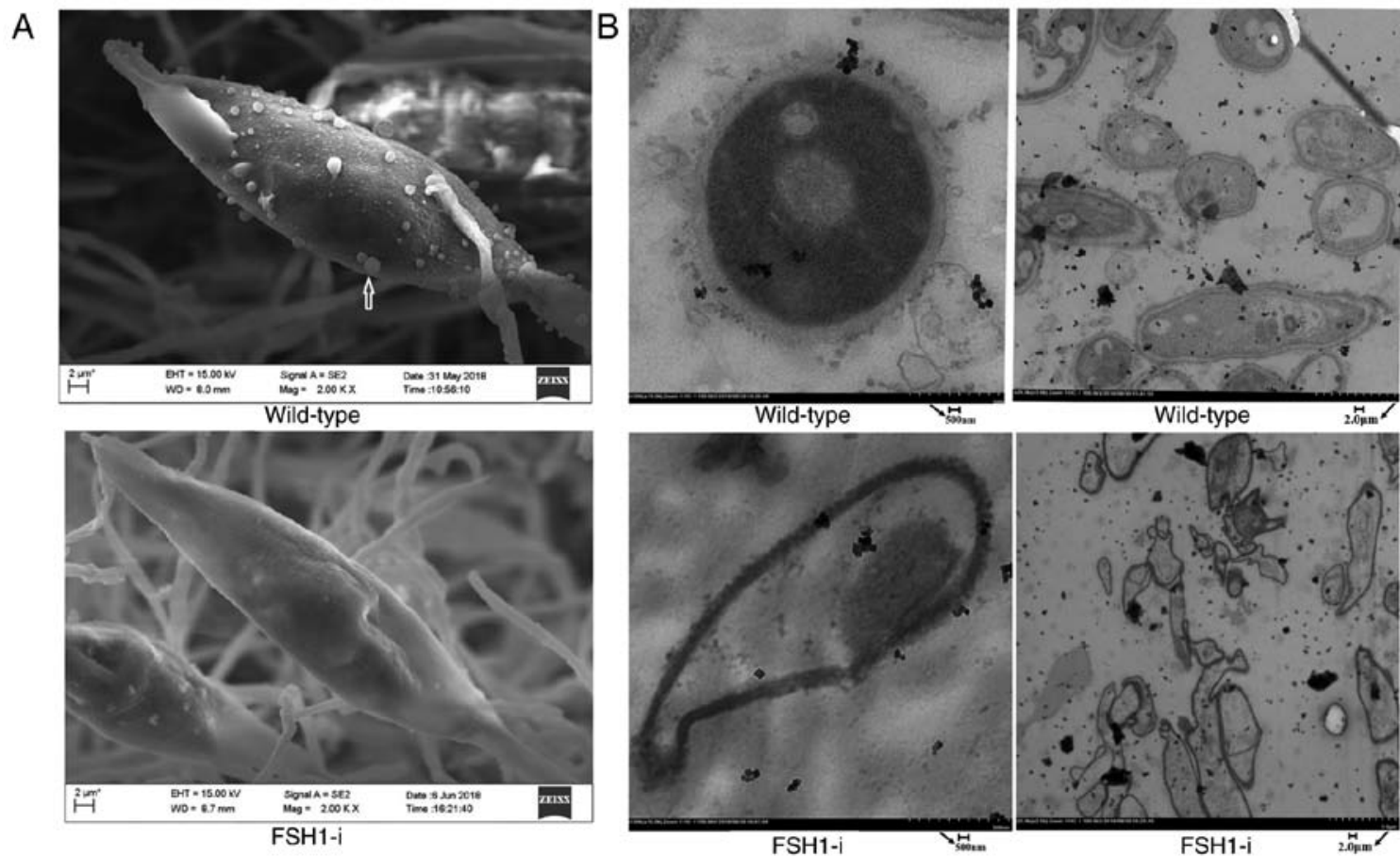

Figure 5. Ultrastructural analysis of wild-type and FSH1-i mutant strains of Microsporum canis by SEM and TEM. (A) SEM micrographs; arrow (on the upper graph) indicates the appearance of papillary nodules (magnification x2,000). (B) TEM images; scale bars represent $500 \mathrm{~nm}$ (left) and $2.0 \mu \mathrm{m}$ (right). The assays were repeated three times. FSH1, family of serine hydrolases 1; FSH1-i, FSH1 RNAi; SEM, scanning electron microscopy; TEM, transmission electron microscopy. 


\section{A}
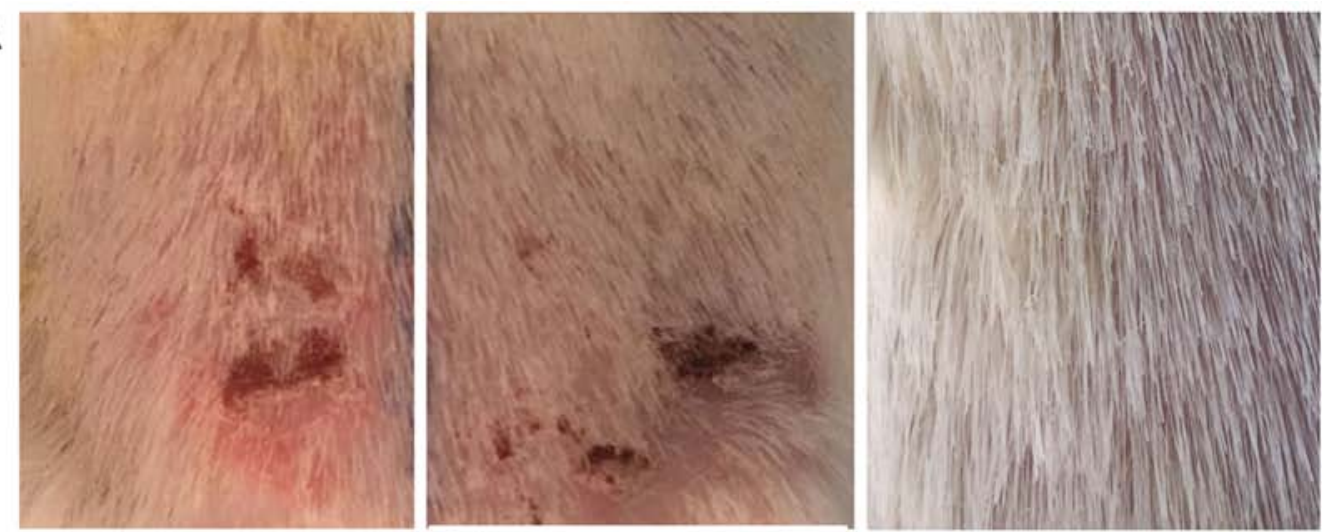

Day 7

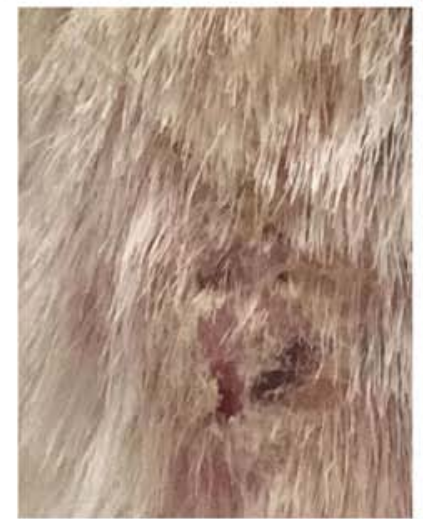

Wild-type

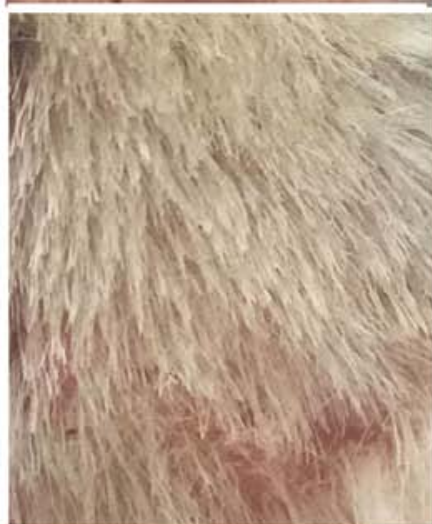

FSH1-i

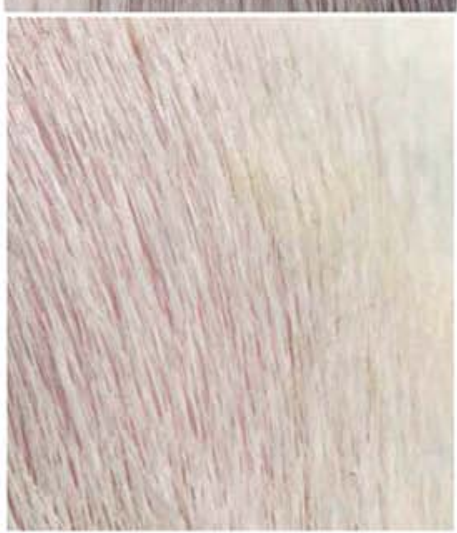

Control
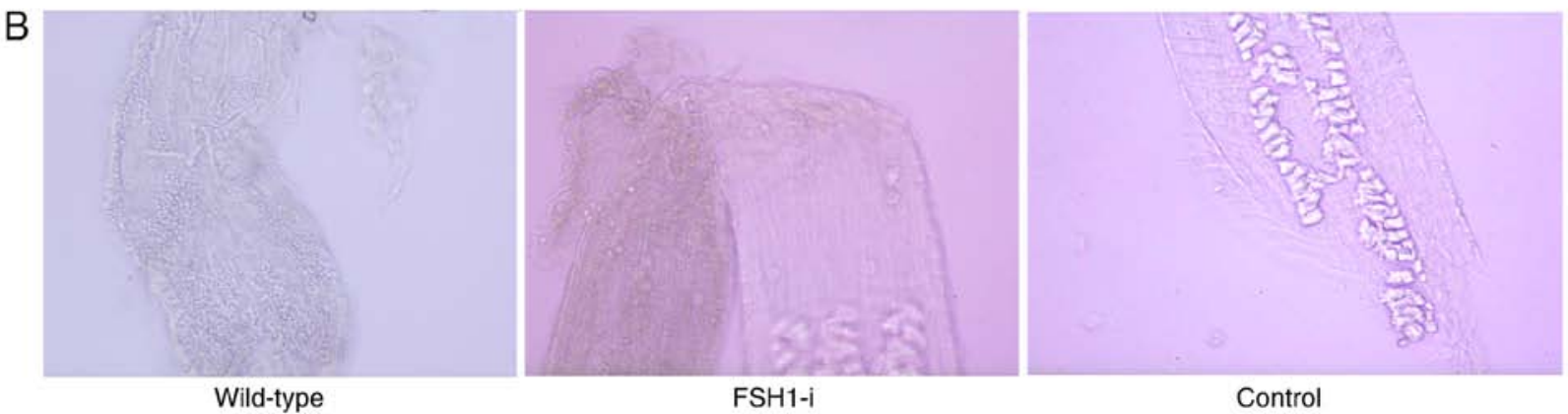

Control

Figure 6. Analysis of guinea pigs infected by Microsporum canis wild-type and FSH1-i strains. The control group were exposed to sterile sodium chloride solution. (A) Images of infected areas on day 7 and 14 post-inoculation. (B) Hair analysis of the infected guinea pigs by light microscopy (magnification x200). Conidia and hyphae were observed in the hair on day 14 post-inoculation. The assays were repeated three times. FSH1, family of serine hydrolases 1 ; FSH1-i, FSH1 RNAi.

a reduced number of papillary nodules of the macroconidia on the surface.

Ultrastructural analysis by TEM. The organelles of the mycelium and macroconidium were examined, and the nuclei and mitochondria appeared normal in shape in the wild-type strain, and the plasma membrane folding was regular and uniform (Fig. 5B). In the mutant strain, significant morphological changes were observed. The majority of the cell membrane appeared irregular and thinner, and there were empty spaces in the cytoplasm. Additionally, cellular structures were partly degraded, and organelles exhibited marked degradation.

Knockdown of FSHI reduces the pathogenicity of M. canis in guinea pigs. Skin infection models were developed in guinea pigs infected with wild-type and FSH1-i mutant $M$. canis. Inflammatory reactions, such as erythema, scales and histopathological changes were measured and recorded. Skin biopsies were taken at day 14 post-inoculation (PI) in the two groups when the inflammatory reaction became prominent. Erythema of skin was first observed at day 4 PI in the guinea pigs inoculated with the $M$. canis wild-type and at day 5 in the guinea pigs infected with $M$. canis FSH1-i mutants. In both M. canis wild-type and FSH1-i mutant group, scurf and red papules were visible on day $7 \mathrm{PI}$, and infiltrative erythema with crusts were seen on day 14 PI. The inflammatory reaction became most prominent on day 14 in both groups. The diameter of the skin erythema lesions were smaller in the animals infected with the FSH1-i strain compared with the animals infected with the wild-type strain (Fig. 6A). Hairs collected from the infected lesions on day 14 were examined after treatment with $10 \% \mathrm{KOH}$. Spores and hyphae were observed in the hair from the skin lesions infected by wild-type and FSH1-i mutant strains. There was no evidence of endothrix spores or 

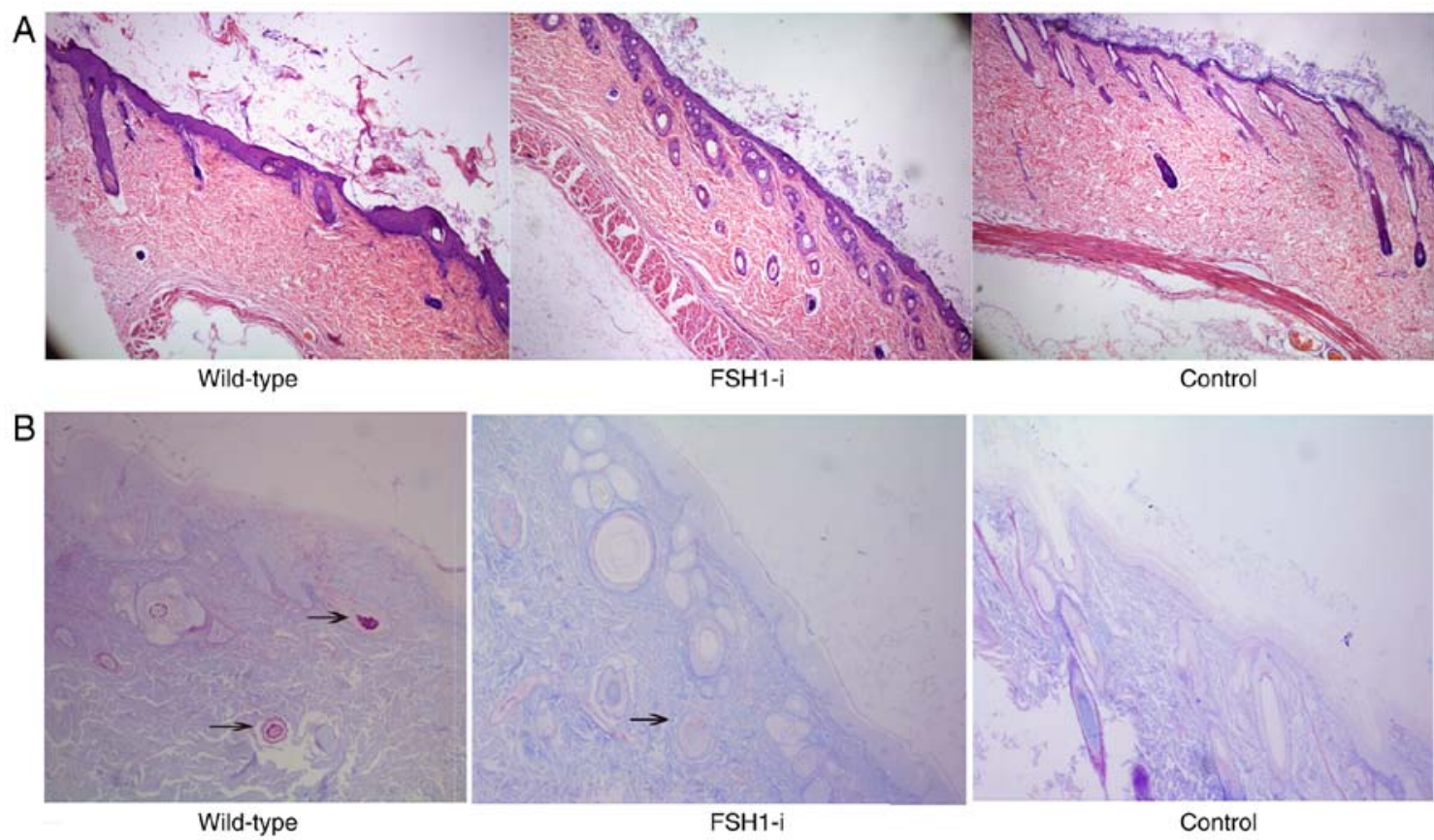

Figure 7. Histopathological analysis of skin biopsies of guinea pigs infected by Microsporum canis wild-type and FSH1-i strains on day 14 post-inoculation. (A) Hematoxylin and eosin staining of skin sections (magnification x40). (B) Alcian blue and periodic acid Schiff staining of skin sections (magnification x100); Conidia and hyphae (arrows) colonized hair follicles on day 14 post-inoculation. The assays were repeated three times. FSH1, family of serine hydrolases 1; FSH1-i, FSH1 RNAi.

hyphae in the control group that had been exposed to sodium chloride instead of the two $M$. canis strains. Considerably more fungal endothrix spores and hyphae were observed in the skin lesions of animals infected with the M. canis wild-type strains compared with the FSH1-i mutants (Fig. 6B). By day $27 \mathrm{PI}$, all the skin lesions disappeared spontaneously in mutant group. However, the lesions remained until day 30 PI in the wild-type group. The skin biopsies were studied by histological examination on day 14 PI. The global scores for the histopathological changes were the sum of the scores of each layer (22). The severity of the inflammation was higher in the wild-type group compared with the FSH1-i mutant group on day 14 PI (Fig. 7A). AB-PAS staining was performed on the tissue sections from the skin lesions. A significantly higher number of conidia in the hair follicles were observed in the wild-type group compared with the mutant group (Fig. 7B).

\section{Discussion}

M. canis is a common pathogen that causes tinea capitis (1). In order to better understand the pathogenic mechanisms underlying tinea capitis, the identification of potential virulence factors in $M$. canis are being investigated. In our previous study, the FSH1 gene was identified as its expression was 44-fold higher when $M$. canis was grown in culture with child scalp compared with child glabrous skin (26). The mRNA expression of FSH1 was higher in $M$. canis strains isolated from tinea capitis lesions compared with tinea corporis lesions when the skin tissue from scalp used as an inducer compared with foreskin (32). These studies suggested that the FSH1 gene may be a potential virulence factor in M. canis.

The full-length cDNA of the FSH1 gene is $945 \mathrm{bp}$, including a 44 bp 5'-untranslated region (UTR), a 70 bp 3'-UTR and a 831 bp open reading frame that encodes a 276 amino acid-long protein (GenBank ID, MK336406). BLAST analysis showed that the cloned full-length sequence of FSH1 cDNA in the current study was $100 \%$ identical to the corresponding sequence encoding the DUF341 domain-containing protein in M. canis (data not shown). Therefore, it was hypothesized that the FSH1 protein was a DUF341 domain-containing protein. The two regions in the domain-containing protein that were consistent with the conserved domains of the FSH1 protein were the abhydrolase and pimeloyl-ACP methyl ester carboxylesterase regions.

To assess the function of the FSH1 gene, expression was knocked down using dsRNAi. Although RNAi has been studied in a number of filamentous fungi, including M. canis (19,39), regulation by Agrobacterium tumefaciens in $M$. canis has not been reported. Construction of an FSH1-i mutant of $M$. canis was challenging. A high transformation frequency was obtained successfully by optimizing conditions in the fungal culture, including temperature, culture medium and the ratio of the different components of the culture.

The size of the colonies in the wild-type strain on SDA did not differ in size to the FSH1-i mutants, suggesting that the $M$. canis wild-type strain and FSH1-i mutant exhibited similar growth rates in vitro. Previous studies regarding potential virulence factors in fungi showed that growth of colonies as determined by colony size was lower and notably delayed following knockdown of a virulent gene (29). The results of the present study demonstrate that the growth of the fungus was not associated with pathogenicity. The coloration of the colony in the wild-type strain appeared more orange compared with the FSH1-i mutant; however, at present there are no studies demonstrating how the colony pigment is produced. The FSH1 gene may be associated with colony pigmentation. Investigation of the microscopic features of the macroconidia and their ultrastructure using 
electron microscopy revealed that the growth features of the fungal strains were different. Typical warted and spindle-shaped macroconidia on the interior portion of each macroconidium was observed with six or more compartments in the wild-type fungi. The FSH1-i mutant however, had a reduced number or absence of septa of the macroconidia. The septa were separated by broad cross-walls, although the function of these walls in M. canis septa is unclear. The present study suggests that the FSH1 gene may be closely associated with growth in $M$. canis, particularly with the formation of macroconidia septation. The FSH1 gene belongs to the family of serine hydrolases that includes serine protease, esterase, amidase and others; FSH1 is a serine esterase $(40,41)$. A previous study reported that the product of the sawD gene, which may be associated with sporulation and pigmentation and particularly with spore septation in Streptomyces ansochromogenes, is homologous to the serine protease of Caulobacter cresceatus (42). Therefore, it was hypothesized that these serine hydrolases, including serine protease and esterase, may be involved in spore formation. Additional research is required to investigate macroconidia differentiation in $M$. canis. The ultrastructural changes of spores and hyphae were studied the FSH1-i mutant using TEM. The FSH1-i mutants exhibited irregular and thin cell membranes, empty spaces in the cytoplasm, degradation of cellular structures and marked destruction of organelles, suggesting that the FSH1 gene may be involved in the stabilization of organelles in M. canis.

Guinea pig models were developed to study the pathogenicity of the FSH1-i mutant compared with the wild-type strain. Animal models were successfully established, and typical signs of $M$. canis infection were identified in the animals. The skin lesions appeared to be fully matured on day 14, consistent with previous studies from Greenberg et al (43) and Zhang et al (44). Numerous fungal conidia were observed in the hair follicles, but not in the epidermis in the wild-type strain group on day 14 , similar to a previous study (22). Conidia and hyphae were present only in the stratum corneum at the start of the experimental period (22). On day $14 \mathrm{PI}$, conidia and hyphae could be seen in hair follicles (22). At the end of the experiment on day 28 , acute and chronic inflammatory cells were completely cleared, leaving behind fibrotic scars at the inoculation sites partially covered by hairs (22). The degree of the inflammatory skin lesions was evaluated by signs on the skin and histopathological features of the biopsies. The diameter of the erythema in FSH1-i mutant group was smaller and the thickness of scale in FSH1-i strains was thinner compared with the wild-type strain group. The number of fungal endothrix spores and hyphae were identified in the hairs of biopsied tissue in the wild-type strain group was higher compared with the FSH1-i strain group, suggesting that the reduction in virulence of $M$. canis resulted from knockdown of the FSH1 gene. The pathology results were evaluated according to the degree of thickening and inflammation of the epidermal layers and dermis thickness of the stratum corneum and the stratum spinosum layers with initial infiltration of inflammatory cells (44). The results of the current study suggested that the pathological changes in the wild-type strain were more severe compared with the FSH1-i mutants on day 14 PI (as determined by the diameter of the red erythema and scales). The present findings also suggested that the wild-type strain resulted in more severe histopathological changes compared with the FSH1-i mutant, consistent with the visualized symptoms of the guinea pigs test results. These results indicate that the FSH1 gene is an important virulence factor for M.canis.

In conclusion, the FSH1 gene was confirmed to be associated with macroconidia septa formation and contributed to $M$. canis virulence. The findings of the present study advance our understanding of the function of the FSH1 gene and provide a foundation for future studies on macroconidia septa and pathogenicity in M. canis. These results suggest that FSH1 gene may be a potential novel target for the development of therapies for M. canis.

\section{Acknowledgements}

The authors would like to thank the Department of Bioengineering, Dalian University of Technology for their support and Qinglong $\mathrm{Hu}$, Department of Pathology, Alegent Creighton Health, Omaha, NE.

\section{Funding}

This study was supported by grants from the National Natural Science Foundation of China (grant nos. 81071330 and 30640016).

\section{Availability of data and materials}

The datasets used and/or analyzed during the current study are available from the corresponding author on reasonable request.

\section{Authors' contributions}

FZ and GY conceived and designed the study. FZ, CT and YX performed the experiments. FZ wrote the paper. GY reviewed and edited the manuscript. All authors read and approved the manuscript.

\section{Ethics approval and consent to participate}

The animal experimental procedures were approved by The Dalian Medical University Animal Ethics Committee. The First Affiliated Hospital of Dalian Medical University Ethics Board approved the use of human tissue in this study, and informed consent from the patient's parents was obtained.

\section{Patient consent for publication}

Not applicable.

\section{Competing interests}

The authors declare that they have no competing interests.

\section{References}

1. Mao L, Zhang L, Li H, Chen W, Wang H, Wu S, Guo C, Lu A, Yang G, An L, et al: Pathogenic fungus Microsporum canis activates the NLRP3 inflammasome. Infect Immun 82: 882-892, 2014.

2. Yu J, Wan Z, Chen W, Wang W and Li R: Molecular typing study of the Microsporum canis strains isolated from an outbreak of tinea capitis in a school. Mycopathologia 157: 37-41, 2004. 
3. Vermout S, Baldo A, Tabart J, Losson B and Mignon B: Secreted dipeptidyl peptidases as potential virulence factors for Microsporum canis. FEMS Immunol Med Microbiol 54: 299-308, 2008

4. Brosh-Nissimov T, Ben-Ami R, Astman N, Malin A, Baruch Y and Galor I: An outbreak of Microsporum canis infection at a military base associated with stray cat exposure and person-to-person transmission. Mycoses 61: 472-476, 2018.

5. Hermoso de Mendoza M, Hermoso de Mendoza J, Alonso JM, Rey JM, Sanchez S, Martin R, Bermejo F, Cortes M, Benitez JM, Garcia WL and Garcia-Sanchez A: A zoonotic ringworm outbreak caused by a dysgonic strain of Microsporum canis from stray cats. Rev Iberoam Micol 27: 62-65, 2010.

6. Binder B, Lackner HK, Poessl BD, Propst E, Weger W, Smolle J and Ginter Hanselmayer G: Prevalence of tinea capitis in southeastern Austria between 1985 and 2008: Up-to-date picture of the current situation. Mycoses 54: 243-247, 2011

7. Del Boz J, Crespo V, Rivas-Ruiz F and de Troya M: A 30-year survey of paediatric tinea capitis in southern Spain. J Eur Acad Dermatol Venereol 25: 170-174, 2011.

8. Costa M, Passos XS, Hasimoto e Souza LK, Miranda AT, Lemos Jde A, Oliveira JG Jr and Silva Mdo R: Epidemiology and etiology of dermatophytosis in Goiânia, GO, Brazil. Rev Soc Bras Med Trop 35: 19-22, 2002 (In Portuguese)

9. Doss RW, El-Rifaie AA, Radi N and El-Sherif AY: Antimicrobial susceptibility of tinea capitis in children from Egypt. Indian J Dermatol 63: 155-159, 2018.

10. Zhu M, Li L, Wang J, Zhang C, Kang K and Zhang Q: Tinea capitis in southeastern China: A 16-year survey. Mycopathologia 169: 235-239, 2010

11. Li C and Liu W: Epidemiology of tinea capitis among children in China in recent years: A retrospective analysis. Chin J Mycol 6 : 77-82, 2011.

12. Yin B, Xiao Y, Ran Y, Kang D, Dai Y and Lama J: Microsporum canis infection in three familial cases with tinea capitis and tinea corporis. Mycopathologia 176: 259-265, 2013.

13. Berg JC, Hamacher KL and Roberts GD: Pseudomycetoma caused by Microsporum canis in an immunosuppressed patient: A case report and review of the literature. J Cutan Pathol 34: 431-434, 2007

14. Anemüller W, Baumgartner S and Brasch J: Atypical Microsporum canis variant in an immunosuppressed child J Dtsch Dermatol Ges 6: 473-475, 2008 (In English and German).

15. Brillowska-Dabrowska A, Michalek E, Saunte DM, Nielsen SS and Arendrup MC: PCR test for Microsporum canis identification. Med Mycol 51: 576-579, 2013.

16. Sharma R, de Hoog S, Presber W and Gräser Y: A virulent genotype of Microsporum canis is responsible for the majority of human infections. J Med Microbiol 56: 1377-1385, 2007.

17. Ayanbimpe GM, Taghir H, Diya A and Wapwera S: Tinea capitis among primary school children in some parts of central nigeria. Mycoses 51: 336-340, 2008.

18. Patel GA and Schwartz RA: Tinea capitis: Still an unsolved problem? Mycoses 54: 183-188, 2011.

19. Baldo A, Mathy A, Tabart J, Camponova P, Vermout S, Massart L, Maréchal F, Galleni M and Mignon B: Secreted subtilisin Sub3 from Microsporum canis is required for adherence to but not for invasion of the epidermis. Br J Dermatol 162: 990-997, 2010.

20. Băguţ ET, Baldo A, Mathy A, Cambier L, Antoine N, Cozma V and Mignon B: Subtilisin Sub3 is involved in adherence of Microsporum canis to human and animal epidermis. Vet Microbiol 160: 413-419, 2012.

21. Baldo A, Chevigné A, Dumez ME, Mathy A, Power P, Tabart J, Cambier L, Galleni M and Mignon B: Inhibition of the keratinolytic subtilisin protease Sub3 from Microsporum canis by its propeptide (proSub3) and evaluation of the capacity of proSub3 to inhibit fungal adherence to feline epidermis. Vet Microbiol 159: 479-484, 2012

22. Shi Y, Niu Q, Yu X, Jia X, Wang J, Lin D and Jin Y: Assessment of the function of SUB6 in the pathogenic dermatophyte Trichophyton mentagrophytes. Med Mycol 54: 59-71, 2016.

23. Grumbt M, Monod M, Yamada T, Hertweck C, Kunert J and Staib P: Keratin degradation by dermatophytes relies on cysteine dioxygenase and a sulfite efflux pump. J Invest Dermatol 133: $1550-1555,2013$

24. Mathy A, Baldo A, Schoofs L, Cambier L, Defaweux V, Tabart J, Maréchal F, Symoens F and Mignon B: Fungalysin and dipeptidyl-peptidase gene transcription in Microsporum canis strains isolated from symptomatic and asymptomatic cats. Vet Microbiol 146: 179-182, 2010.
25. Nakayashiki H: RNA silencing in fungi: Mechanisms and applications. FEBS Lett 579: 5950-5957, 2005.

26. Zhang FR, Zhang Y, Zhang ZY, Yang GL, Jing LJ and Bai YG Analysis of the differentially expressed genes in Microsporum canis in inducing smooth skin and scalp tissue conditions. Clin Exp Dermatol 36: 896-902, 2011.

27. Gräser Y, EI Fari M, Vilgalys R, Kuijpers AF, De Hoog GS, Presber $\mathrm{W}$ and Tietz $\mathrm{H}$ : Phylogeny and taxonomy of the family arthrodermataceae (dermatophytes) using sequence analysis of the ribosomal ITS region. Med Mycol 37: 105-114, 1999.

28. Jackson CJ, Barton RC and Evans EG: Species identification and strain differentiation of dermatophyte fungi by analysis of ribosomal-DNA intergenic spacer regions. J Clin Microbiol 37: 931-936, 1999.

29. Zhang Z, Hou B, Wu YZ, Wang Y, Liu X and Han S: Two component histidine kinase DRK1 is required for pathogenesis in sporothrix schenckii. Mol Med Rep 17: 721-728, 2018.

30. Zhang P, Xu B, Wang Y, Li Y, Qian Z, Tang S, Huan S and Ren S: Agrobacterium tumefaciens-mediated transformation as a tool for insertional mutagenesis in the fungus penicillium marneffei. Mycol Res 112: 943-949, 2008.

31. Livak KJ and Schmittgen TD: Analysis of relative gene expression data using real-time quantitative PCR and the 2(-Delta Delta C(T)) method. Methods 25: 402-408, 2001

32. Basma AA, Zuraini Z and Sasidharan SA: Transmission electron microscopy study of the diversity of Candida albicans cells induced by Euphorbia hirta L. Leaf extract in vitro. Asian Pac J Trop Biomed 1: 20-22, 2011.

33. Wang F, Tao J, Qian Z, You S, Dong H, Shen H, Chen X, Tang S and Ren S: A histidine kinase PmHHK1 regulates polar growth, sporulation and cell wall composition in the dimorphic fungus Penicillium marneffei. Mycol Res 113: 915-923, 2009.

34. Jin XJ, Wang AP, Qiao JJ, Liu W, Wan J, Wang XH, Wu LS and Li RY: Establishment of an animal model of dermatophytosis and evaluation of the antifungal efficacy on dermatophytosis with this model. Chin J Dermatol 42: 125-128, 2009 (In Chinese).

35. Silverman J and Muir WW III: A review of laboratory animal anesthesia with chloral hydrate and chloralose. Lab Anim Sci 43: 210-216, 1993.

36. Olszewski J: Guinea pig as often object to otoneurological experimental examinations. Otolaryngol Pol 61: 838-841, 2007 (In Polish).

37. Mao N, Gao Q, Hu H, Zhu T and Hao L: BPA disrupts the cardioprotection by $17 \beta$-oestradiol against ischemia/reperfusion injury in isolated guinea pig hearts. Steroids 146: 50-56, 2019.

38. Zhou Y, Song J, Wang YP, Zhang AM, Tan CY, Liu YH, Zhang ZP, Wang Y, Ma KT, Li L and Si JQ: Age-associated variation in the expression and function of TMEM16A calcium-activated chloride channels in the cochlear stria vascularis of guinea pigs. Mol Med Rep 20: 1593-1604, 2019.

39. Vermout S, Tabart J, Baldo A, Monod M, Losson B and Mignon B: RNA silencing in the dermatophyte Microsporum canis. FEMS Microbiol Lett 275: 38-45, 2007.

40. Quevillon-Cheruel S, Leulliot N, Graille M, Hervouet N, Coste F, Bénédetti H, Zelwer C, Janin J and Van Tilbeurgh H: Crystal structure of yeast YHR049W/FSH1, a member of the serine hydrolase family. Protein Sci 14: 1350-1356, 2005.

41. BaxterSM, Rosenblum JS,Knutson S,Nelson MR, Montimurro JS, Di Gennaro JA, Speir JA, Burbaum JJ and Fetrow JS: Synergistic computational and experimental proteomics approaches for more accurate detection of active serine hydrolases in yeast. Mol Cell Proteomics 3: 209-225, 2004.

42. Gang L, Wei C, Yuqing T, Huarong T, Chater KF and Buttner MJ: A novel gene: sawD related to the differentiation of streptomyces ansochromogenes. Chin J Biotechnol 15: 195-202, 1999.

43. Greenberg JH, King RD, Krebs S and Field R: A quantitative dermatophyte infection model in the guinea pig-a parallel to the quantitated human infection model. J Invest Dermatol 67: 704-708, 1976

44. Zhang X, Wang Y, Chi W, Shi Y, Chen S, Lin D and Jin Y: Metalloprotease genes of Trichophyton mentagrophytes are important for pathogenicity. Med Mycol 52: 36-45, 2014.

This work is licensed under a Creative Commons Attribution-NonCommercial-NoDerivatives 4.0 International (CC BY-NC-ND 4.0) License. 